\title{
The dawn of the information age in least developed countries (LDCs): lessons learned from four case studies
}

\author{
Robert M. Bichler
}

ICT\&S Center for Advanced Studies and Research in Information and Communication Technologies \& Society, University of Salzburg, Sigmund-Haffner-Gasse 18, 5020 Salzburg, Austria, robert.bichler@sbg.ac.at, +436628044 4822

\begin{abstract}
The emerging information age is characterized by the ubiquitous availability of information and communication technologies. While in highly developed countries, due to heavy investments in the telecommunication infrastructure, the public and scientific discussion more and more focuses on the so-called digital divide 2.0, i.e. the lack of ICT skills, for developing countries both, the access to and the use of ICTs still remain a huge challenge.

The goal of my dissertation thesis is to highlight these challenges, as well as the opportunities that occur for Least Developed Countries (LDCS) on their way towards an information society. The study examines ICTs in four geographically and culturally diverse regions, including the countries Yemen, Guatemala, Malawi and Lao PDR, on the macro and on the micro level. The research on the macro level is guided by the central research question: Are ICTs in LDCs used to foster societal development or are they reinforcing imperialistic patterns of Western hegemony?

On the micro level the project aims to investigate the users' demographics, their habits of ICT use, as well as the barriers and opportunities for the citizens emerging from the upcoming information age. The findings from the macro and the micro level will be correlated on the basis of the five dimensions of society (ecological, political, cultural, economical and technological) to assess the state of the art and to formulate strategies to counter the current eColonialism tendencies and to foster a sustainable implementation of ICTs in LDCs.
\end{abstract}

Keywords: Information and Communication Technologies, Least Developed Countries, Sustainability, eColonialism

Acknowledgement: I want to thank Prof. Wolfgang Hofkirchner for making this project possible and for his valuable input throughout my research.

D uring the last ten years an increasing body of literature, dealing with the relationship between Information and Communication Technologies (ICTs) and development, has been emerging (cf. e.g. Mansell \& Wehn, 1998; Braga et al., 2000; Okpaku, 2003; Wilson, 2004). Especially for developing countries the challenges implicated with the so called information revolution are enormous and until today the question how developing countries should react to this remains open. Developing countries are facing the danger that the already existing tremendous gap may still widen and that they are falling even more behind the forerunners of the emerging information capitalism. In this paper I argue that the (post)-industrialised high-income economies in the West are failing to do something against this development, because they are gaining profit out of this situation. It will be demonstrated how developed countries benefit in certain ways at the expense of the developing world. In the following I will draw an outline of my dissertation thesis in which I am going to show how the rise of Information and Communication Technologies (ICTs) originates a new form of colonialism and I will try to propose strategies to counter this development by implementing ICTs in a sustainable manner. The thesis is based on theoretical considerations, as well as on empirical field studies in four different 
countries, namely Guatemala, Lao PDR, Malawi and Yemen.

Initially, a brief introduction of the sustainability concept will be given, followed by a more elaborated working definition. In section 3 I will give a review on the current situation of ICTs for development, before the concept of eColonialism will be introduced in chapter 4 . Section 5 addresses the question how to counter the existing hegemonic tendencies with the goal to achieve a Global Sustainable Information Society (GSIS). The methodology, which was applied in the field research, will be presented in chapter 6, before I sum it up in a conclusion.

\section{Sustainability}

In Western societies the term sustainability has been en vogue in the scientific, as well as public debate, for the last three decades, especially in the context of ecology. Due to the rise of neoliberalism in the 1980s, the meaning of the term was broadened. From that time on economy has been included in the sustainability debate, whereas the meaning of sustainability in that sense refers mainly to economic growth and corporate benefits and neglects economic wealth for the citizens. To counter this purely neoliberal understanding, both scientist and politicians, introduced social sustainability as a third pillar (cf. Serageldin, 1995). These components make up the so-called "triangle of sustainability". In this paper I argue that this triangle still lacks several constituents, which are crucial especially if one wants to formulate recommendations for the sustainable implementation of ICTs for development.

\subsection{Sustainability Debate}

In 1987, the WCED (World Commission on Environment and Development), chaired by the former Prime Minister of Norway Gro Harlem Brundtland, published the so called "Brundtland Report". The report gave much attention to the challenges of overcoming poverty and meeting basic needs, as well as integrating the environment into economic decision-making processes (cf. WCED, 1987). The WCED defined sustainable development as "development that meets the needs of the present without compromising the ability of future generations to meet their own needs" (WCED, 1987, p. 43).

In the discourse on sustainability, there has been a shift from a focus on ecological issues towards the inclusion of broader societal issues. The "triangle of sustainability", introduced by the World Bank, has been very important in bringing the discussion on sustainability from purely ecological aspects further towards a more integrative concept. Ismail Serageldin, later vice-president of the World Bank, identified an economic, a social, and an ecological dimension of sustainability. "It is not surprising that these concerns reflect the three sides of what I have called the 'triangle of sustainability'-its economic, social, and ecological dimensions" (Serageldin, 1995, p. 17). The European Union, the United Nations and other transnational organisations nowadays concordantly identify an ecological, an economic, a social, and an institutional dimension of sustainability. Another crucial time period was between the 1992 UN Conference on Environment and Development ("Earth Summit") in Rio de Janeiro, Brazil, and the 2002 World Summit on Sustainable Development (WSSD) in Johannesburg, South Africa. "At the time of Rio, sustainable development was mainly about protecting nature, but now, in the wake of Johannesburg, it is first and foremost about protecting people" (World Summit on Sustainable Development, 2002, p. 22).

If sustainability is conceived as a complex phenomenon, then it includes various aspects that need to be achieved in sustainable social systems, such as individual well-being, security, freedom, and self-determination just like collective dimensions such as wealth for all, social security for all, political participation for all, or health and education for all (cf. Fuchs \& Blachfellner \& Bichler, 2007, p. 304). Therefore the "triangle of sustainability" must be broadened by including cultural and technical sustainability. These five components make up the "pentagon of sustainability". 


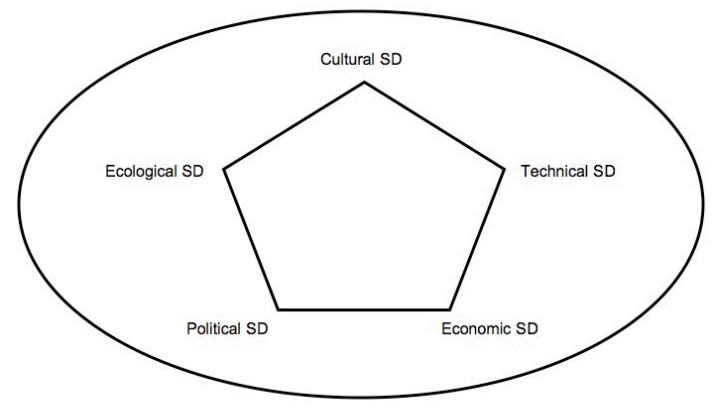

Figure 1: The Pentagon of Sustainability (Bichler, 2007, p. 350)

\subsection{A working Definition of Sustainability}

In order to advance a non-reductionistic, integrative, complex understanding of sustainability, the following working definition is proposed:

Sustainable societal development satisfies the needs of current and future generations; a sustainable society is a society that is based on ecological sustainability (e.g. ecological conservation, stability in the area of health), political sustainability (e.g. political participation, peace), cultural sustainability (e.g. stability in the area of education, selfdetermined life-styles), economic sustainability (e.g. material wealth) and technological sustainability (e.g. usability and wise use) (cf. Fuchs \& Blachfellner \& Bichler 2007 , p. 304). The question, which emerges is, how ICTs can be used to enhance the sustainability of all five subsystems to ensure societal well-being.

\section{On ICTs for Development}

If one reviews the current literature on ICTS for Development it is getting clear that two central viewpoints form the focus of discussion: on the one hand the opportunities are highlighted, whereas on the other hand the risks are dominant. Braga et al. (2000, p. 1) for example state for developing countries that "[...] the challenges are substantial. The possibility that the gap already existing between the front-runners of the networking revolution (mostly high-income economies) and those lagging behind (mostly low-income countries) may still grow larger, raises the spectre of a 'digital divide'. The concern here is not restricted to the issue of connectivity per se; it also includes the implications of connectivity (or lack of it) for economic growth and the broader agenda of sustainable development. The danger faced by all is that digital divide may reinforce patterns of divergence both internationally and within countries". The authors also stress the "digital opportunities", which go side by side with the challenges for developing countries, when they point out that developing countries "[...] can scientifically benefit from investments in modern information infrastructure in a procompetitive regulatory environment, and leapfrog stages of development in terms of networking roll-out" (Braga et al., 2000, p. 12). This neoliberal understanding is purely focused on economic benefit resulting out of competition. The idea behind it is that economic development based on free, deregulated markets will automatically lead to societal progress and wealth for all. The developing countries should adopt the Western economic system, monitored by institutions such as the World Bank, which includes large privatization activities. This approach actually does not support developing countries on their way to an inclusive information society, in contrary; it favors and strengthens Western economic and cultural hegemony. Modernization theoretical approach are criticized by a number of scholars. For example Ngwenyama et al. conclude that "[...] decades of the IMF and World Bank's austere policies and the more recent privatization programs on the health, education and civil infrastructure have had a devastating impact on many developing countries" (2006, p. 7). Boyd-Barrett demonstrates this for the USA, which "[...] increasingly pursued national interest through submissive agencies, notably the World Bank, IMF and G7, where NWO policies promoted free trade, capital and information flows, that gave free reign to the global expansion of Western corporations, supported by a US defense-incubated 'secret weapon' networked microprocessor technologies". (Boyd-Barrett, 2006, p. 24) The same logic is quite often applied when it comes to the 
implementation of ICTs, especially in Africa where the connectivity issue, due to the lack of fiber cables, is central. "In West Africa the fiber is already there, but the price is still around 3000 Dollars per megabit/s per month. It has to do with the companies that build the fiber and the amount of return they get for their investment. Fiber connections are big business, not controlled by the government." (P. B. Nyirenda, personal communication, November 20, 2007) Like in other African countries, government does not any longer control the IT infrastructure sector. Companies from outside, mainly from the Western world, are building the infrastructure. In the case of Malawi, Alcatel-Lucent is authorized by the Malawian government to establish the connection to Mozambique. ( $P$. B. Nyirenda, personal communication, November 20, 2007). Yunusa Z. Ya'u (2005, p. 110) in his article Globalisation, ICTs, and the New Imperialism: Perspectives on Africa in the Global Electronic Village sums up such developments: "While African countries that have undertaken the liberalisation of the telecommunication sector have ended state monopolies they have suddenly found themselves saddled with a new monopoly: that of the foreign investors. The AITEC report on the state of ICT infrastructure in Africa for the year 2000 (Hamilton 2002) clearly shows this trend." Western companies mainly drive the implementation of the telecommunication infrastructure. The shareholders of Malawi Net for example are US Comnet with $64 \%$ and the Malawian company MTL with $36 \%$. Celtel, the main mobile phone provider, belongs to Zain (formerly MTC), an international corporate group based in Kuwait. Celtel has built networks in 15 African countries and covers more than a third of the population of Africa.

There is not only an economic version of the leapfrogging thesis in the academic discourse, but also a technical one. In the latter meaning the thesis states that developing countries can overleap certain stages of development by using mobile technologies (e.g. Castells et al., 2006, p. 216). In my opinion this thesis implies a couple of shortcomings. First of all a ubiquitous diffusion of handhelds in combination with an adequate infrastructure, i.e. a functioning GPRS, UMTS or EDGE network, must be seen as a basic condition. In developing countries, even more dramatically in Least Developed Countries (LDCs) ${ }^{1}$, both components are only given in urban areas, where the economy acts as a driving force for the implementation of telecommunications infrastructure. Nonetheless, the question of affordability still remains open. In recent years mobile phones became huge phenomena in the developing world. In 2007, Malawi for instance had 175.209 main telephone lines subscribers (fixed line penetration: 1.35) and with a number of 944.503 nearly six times more mobile cellular phones (cf. MACRA, 2007). Due to the low financial capacity of the citizens, mobile phone use is almost exclusively in form of prepaid services. This results in the use of mobile phones primarily to receive calls, which also manifests in the language use in everyday life. In India, for example, it is common to "give somebody a missed call"; meaning that instead of carrying out a phone call, one only lets the phone ring. I observed the same phenomena in Malawi, where the phrase "I flash you" found its way into daily conversation.

Internet access via a mobile phone, in case the service is available, is still very expensive and therefore demands a high amount of credit on the prepaid card. In Malawi for example, mobile airtime is three times more expensive than the already very expensive fixed line costs. Besides the infrastructure and costs aspects, the needed Internet skills and the lack of awareness for using the Internet are main barriers.

\section{3. eColonialism}

It is getting clear that the implementation of ICTs in developing countries can be seen as a hegemonic project, mainly driven by capitalist accumulation and the generation and expansion of markets at the cost of the citizens. Such a neoliberal form of economy therefore colonizes and exerts a dominating influence on the political, the cultural, the environmental as well as the technical subsystem of society. Under the term eColonialism in this context I understand two

\footnotetext{
${ }^{1}$ For a definition of LDCs see chapter 6. Reflecting on my Research
} 
mutual interacting processes: Following Habermas, I define colonization as a process, in which instrumental rationality spills from the economic sub-system over to other areas of life and "[...] achieves dominance there at the expense of moral-practical and aestheticalpractical rationality" (Habermas, 1987, p. 304). Globalization, which for Sloterdijk (2006, p. 58) always means Westernization, and therefore Western hegemony, shapes this ongoing development with the goal of "[...] constituting international information and resource flows in a fashion most suitable to the expansion of multinational capital" (Alleyne, 1999, p. 369). I term this process that is a combination of commodification and globalization in the context of the implementation of ICTs in developing countries eColonialism. Originally Thomas McPhail coined the term in his book Electronic Colonialism: the Future of International Broadcasting and Communication, which was published in 1981. In his understanding eColonialism "[...] explains how media are collectively influencing the minds, attitudes, values, and life-styles of a global audience" (McPhail, 2008, p. 45). His thesis primarily focuses on Western, mainly US driven, influence on different cultures by means of ICTs: "From Timbuktu to Katmandu, a global culture of MTV, Sponge-Bob, The Simpsons, Google, and the latest Hollywood blockbusters are spreading in unison with the global economy." (McPhail, 2008, p. 45)

In my opinion eColonialism is not only a cultural phenomenon, which is interrelated with the global economy, rather it is a much more complex interplay between the subsystems of society. Economic driven eColonialism therefore manifests in political, cultural, ecological and technical eColonialization tendencies that will be specified in the following sections.

\subsection{Political eColonialization}

Political eColonialization is realized through forcing developing countries to adopt the Western capitalist's system, which puts pressure on these countries to join international institutions and agreements. Boyd-Barrett argues that ICTs sustain the Western driven globalization by gaining profit from hardware, software and services, which are protected by patents and Intellectual Property Rights (IPR) (cf. Boyd-Barrett, 2006, p. 28). IPRs are a crucial issue in this context, since they are obligatory for accession to WTO membership or even more importantly, to funding from e.g. the World Bank or the International Monetary Fund. The World Intellectual Property Organization (WIPO) is a UN agency with a mandate to harmonize intellectual property rights across the member states. Recently WIPO has developed a plan to harmonize patents, which has tremendous consequences for developing countries. Carlos Correa in his critiques summarizes: "[...] harmonized standards would leave little room for developing countries to adapt their patent laws to local conditions and needs; harmonization would take place at the highest level of protection (based on standards currently applied by developed countries, especially the United States and Western European countries) meaning that the process will exert an upward force on national laws and policies in developing countries resulting in stronger and more expansive rights of the patent holders with the corresponding narrowing of limitations and exceptions. Such higher standards are unlikely to have a positive effect on local innovation in developing countries; and also the danger that the current draft contains standards that are primarily aimed at benefiting the 'international industries' and not individual inventors or small and medium size enterprises." (Correa, 2004, p. 9)

\subsection{Cultural eColonialization}

Cultural eColonialization becomes manifests in the domination of electronic networks by Western content. My study shows that the Internet applications provided by google, yahoo and $m s n$ are by far the most used ones. All three companies are based in the USA, which illustrates the US hegemony concerning Internet content and supports Boyd-Barrett's findings that major "[...] US portals such as AOL and Yahoo! governed access to a web dominated by US Englishlanguage sites, many fed by such US news organisations as AP, CNN and MBC" (2006, p. 30). Since in developing countries there is 
hardly any content in the local language, the predominant language remains English. My study in Yemen for example demonstrates that $52 \%$ of the respondents used Internet services in Arabic and $46 \%$ in English (Bichler, 2007, p. 356). In Malawi the situation is even more distinct, given that $99 \%$ of the study participants used Internet services in English, although a more dominant language is Chichewa (Bichler, 2008b, p. 49). In order to be able to use the full potential of the Internet, it is necessary to know at least Basic English. The domination of Western content providers comes along with the propagation of the Western life style concerning different spheres of life. Norms and values, which manifest in e.g. the Western understanding of democracy, work routines, religious views, personal relationships, etc. are distributed globally and enforce the Western claim to power. The rise of fundamental Islamic terrorism can be seen as one reaction to this development.

\subsection{Ecological eColonialization}

The ICT industry follows the same rules as all other parts of industry. In the emerging information society there is still a tremendous demand for material goods, which lay the basis for the necessary infrastructure such a society depends on. Christian Fuchs is in my opinion absolutely right when he argues: "The knowledge society is not an immaterial society, but a new phase in the material reality of capitalism. It requires a large material infrastructures made up by computers, periphery, servers, routers, switches, network cables, etc." (Fuchs, 2006, p. 45) ICTs are industrial products, their production and disposal requires raw materials on the one hand and generates waste and emission on the other hand. "One study showed that the production of the average computer chip requires 45,46 liters of water, used primarily for washing. One chip plant in the USA uses between 4,5 and 13,5 million liters of water a day." (EITO, 2002, p. 255) Furthermore Eric D. Williams et al. (2002, p. 5509) state: "The lower bound of fossil fuel and chemical inputs to produce and use one 2-gram microchip are estimated at $1600 \mathrm{~g}$ and $72 \mathrm{~g}$, respectively. Secondary materials used in production total
630 times the mass of the final product, indicating that the environmental weight of semiconductors far exceeds their small size." Considering the rapid worldwide diffusion of electronic devices such as PCs, mobile telephones and entertainment electronics in recent decades, the question how to deal with the resulting waste has come up. The main solution was found in ecological eColonialization, where the industrialized countries simply export their waste to the developing world, even though the Basel Convention restricts transboundary trade of ewaste. One of the main destinations for ewaste is Asia (see Fig. 2). From non-ratifying countries, such as the USA, estimates have been made that $50-80 \%$ of the domestic ewaste is not recycled domestically but instead shipped to destinations such as China (cf. Widmer et al., 2005, p. 443).

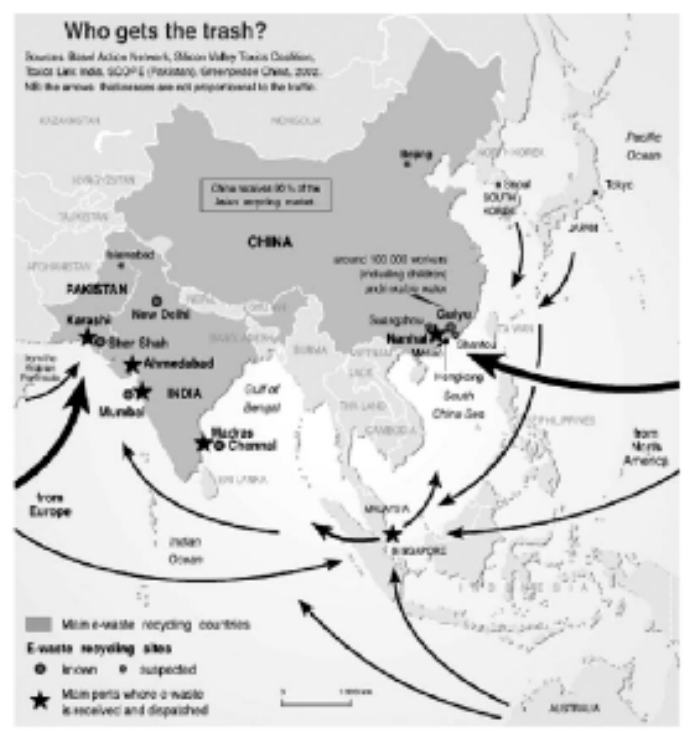

Figure 2: Asian e-waste traffic (Schwarzer et al., 2005)

\subsection{Technical eColonialization}

The global US dominance of the IT sector is an expression of technical eColonization: "For the last five decades, U.S. scientific innovation and technological entrepreneurship have ensured the country's economic prosperity and military power. It was Americans who invented and commercialized the semiconductor, the personal computer, and the Internet; other countries merely followed the U.S. lead ... The United States 
also leads the major technology markets, holding commanding market shares in aerospace, scientific instruments, computers and office machinery, and communications instruments. U.S. information and communication technology producers lead almost every sector. And for the last two decades, U.S. firms have been the top providers of high-technology services, accounting for about one-third of the world's total." (Sigal, 2004, p. 2; as cited in BoydBarrett, 2006, p. 28)

On the forefront of this development are corporate groups such as Microsoft, but interestingly also supported by globally active non-governmental organizations. UNESCO for example launched in 2004 an opensoftware project, sponsored by Microsoft.

The agreement defines eight areas in which UNESCO and Microsoft work together in different developing projects:

- education and learning

- community access and development

- cultural and linguistic diversity and preservation

- digital inclusion and capacity

- exchange and promotion of best practices on the use of ICT for socio-economic development

- fostering web-based communities of practice, including content development, knowledge sharing and empowerment through participation

- facilitating exchange of information and of software applications

- sharing expertise and strategies (cf. UNESCO, 2004)

In principle the eight areas sound highly promising, but it is quite self-evident that the projects are based on Microsoft's know-how and therefore on Microsoft products. The developing world will become a huge IT market in the next years and Microsoft probably would not relinquish it to initiatives such as Negroponte's One Laptop per Child project and therefore it might be possible that Microsoft uses such co-operations to prepare the market entry to sell their already existing products, which are based on patterns of use prevalent in the (post)-industrialized countries. Moreover, the question how sustainability can be achieved once the funding expires remains open.

\section{How to counter these tendencies?}

So far I have argued that the implementation of ICTs in developing countries is antidemocratic because it is mainly carried out by the (post)-industrialized Western world and primarily benefits the latter, whereas the costs are far more widely distributed.

Following the understanding of sustainable development argued in this paper, such a one-sided hegemonic approach is the opposite of sustainability and does not at all satisfy the needs of current and future generations. Already in 1998, Robin Mansell and Uta Wehn have introduced an alternative approach in their book Knowledge Societies. Information Technology for Sustainable Development. The focus here lays on ICT applications that could assist developing countries to reap the "[...] social and economic benefits associated with extremely rapid innovation in advanced ICT-based goods and services" (Mansell \& When, 1998, p. 82). The authors discuss a number of ICT applications, which they consider to be appropriate to enhance a broader understanding of sustainability. This list of applications includes e-government, elearning, e-travelling, e-transport, e-health, eeducation and e-inclusion. Christian Fuchs is right when he argues: "These are technologies that today are mainly developed in Western countries and benefit the latter." (Fuchs, 2006, p. 49) But still, the attempt to broaden the discussion and the formulation of concrete areas of applications points into the right direction. 


\begin{tabular}{|c|c|}
\hline Dimension & Strategy for ICT use \\
\hline Economic Dimension & Wealth for all through new job opportunities \\
\hline Political Dimension & $\begin{array}{l}\text { - International funding for development without neoliberal obligations } \\
\text { - e-government services in form of involvement of citizens through } \\
\text { participation instead of purely providing information } \\
\text { - Open Source products instead of Intellectual Property Right patents } \\
\text { - Open access to Internet services and applications instead of restrictions } \\
\text { (e.g. unpayability, blocking of websites) }\end{array}$ \\
\hline Cultural Dimension & $\begin{array}{l}\text { - Content in local language } \\
\text { - ICT awareness through education: well directed ICT training programs } \\
\text { instead of self-undirected learning by doing } \\
\text { - e-learning applications as a chance to bring education to rural areas }\end{array}$ \\
\hline Ecological Dimension & $\begin{array}{l}\text { Using cognitive and communicative features of ICTs to raise the } \\
\text { awareness of ecological conservation and health related issues }\end{array}$ \\
\hline Technological Dimension & $\begin{array}{l}\text { Improved usability: the design of applications, which are easy to use and } \\
\text { appropriate to the region }\end{array}$ \\
\hline
\end{tabular}

Figure 3: ICTs for Sustainable Development

Following Christian Fuchs (2006), I contend in this paper that a sustainable society is based on ecological, political, cultural, economical and technological sustainability. Thus ICTs should be used in a way that fosters sustainable development in each dimension with the goal to achieve a Global Sustainable Information Society (GSIS).

A GSIS is a society, firstly, which is planetary in scale; secondly, which is collectively intelligent so as to be able to come to grips with problems that arise from its own development; and, thirdly, which is making use of modern information technologies and media in just that context and for the sake of it (cf. Hofkirchner et al., 2007, p. 25).

In Figure 3, the described eColonialism tendencies are inverted and further, promising strategies for the sustainable use of ICTs are assigned, in line with the GSIS approach, to the five dimension of sustainable development.

\section{Reflecting on my Research}

The Economic and Social Council of the United Nations uses three criteria, which a country must satisfy, for the identification of LDCs:

- "a low-income criterion, based on a threeyear average estimate of the gross national income (GNI) per capita (under $\$ 750$ for inclusion, above $\$ 900$ for graduation);

- a human resource weakness criterion, involving a composite Human Assets Index (HAl) based on indicators of: (a) nutrition; (b) health; (c) education; and (d) adult literacy; and

- an economic vulnerability criterion, involving a composite Economic Vulnerability Index (EVI) based on indicators of: (a) the instability of agricultural production; (b) the instability of exports of goods and services; (c) the economic importance of non-traditional activities (share of manufacturing and modern services in GDP); (d) merchandise 
export concentration; and (e) the handicap of economic smallness (as measured through the population in logarithm); and the percentage of population displaced by natural disasters."

(United Nations, 2002-2005)

The goal of the study is to examine ICTs in LDCs on the macro, as well as on the micro level. The research on the macro level is guided by the central research question:

Are ICTs in LDCs used to foster societal development or are they reinforcing imperialistic patterns of Western hegemony?

On the micro level the study aims to investigate the users' demographics, their habits of ICT use, as well as the barriers and opportunities for the citizens emerging from the upcoming information age.

The findings from the macro and the micro level will be correlated on the basis of the five dimensions of society (ecological, political, cultural, economical and technological) to assess the state of the art of ICTs in the selected countries and to find ways to further implement them in a sustainable manner. The study examines the situation in four geographically and culturally diverse regions, including the countries Yemen, Guatemala, Malawi and Lao PDR. The selection process was guided by the question if there are any common barriers, which are regionally and culturally independent, or if they are solely context dependent. All four case studies are completed and selected results of the studies in Yemen and Malawi have already been published (Bichler, 2007; 2008a; 2008b).

The study combines quantitative and qualitative methods. The primary data were drawn from four surveys of users in Internet cafés in the capitals of the selected countries between January 2007 and March 2008. Internet cafés were chosen because the Internet penetration in three of the selected countries (Lao PDR, Malawi and Yemen) is only between $0.4 \%$ and $1.3 \%$ of the total population $^{2}$ and therefore Internet cafés seemed to be the ideal place to find out about the Internet habits of those who actually use the Internet. Guatemala is with a diffusion rate

\footnotetext{
${ }^{2}$ Source: internetworldstats.com, 2008
}

of $10.4 \%$ an exception. The country does not belong to the LDCs and was chosen as an object of research for two reasons: first of all I want to draw a comparison between LDCs and a country that belongs to the group of medium-developing countries to find out about common or different problems as well as shared opportunities. Secondly, the only country on the American continent, which belongs to the LDCs, is Haiti. Due to the ongoing civil unrests it has been impossible for me to conduct a survey in the country.

The Internet cafés, as well as the respondents, were chosen randomly distributed over the capitals of the selected countries. After an introduction of my research project, the Internet café managers agreed on my intention to distribute the questionnaires to the clients. In each country, I personally handed out the questionnaires and in total 270 completed ones were given back to me in each country, making up a total of 1080 questionnaires.

Similar to a study taken out by Peter G. Mwesige (2004) in Ugandan Internet cafés, the questionnaire contained both, open-ended and closed questions that were tested in a small pre-test study at the ICT\&S Center of the University of Salzburg. Besides using the questionnaires to find out about quantitative aspect, they were also used in a qualitative way, focusing on different forms of Internet use.

In addition, expert-interviews with decisionmakers from governmental institutions, universities, business companies and NGOs were carried out to gain a broader picture.

To round the research off, Internet café managers were interviewed to discuss their views of the Internet in their countries. These interviews were very fruitful to gain a deeper understanding about the role of the Internet in the studies countries, especially concerning Internet usage. The language barrier was a bit of a problem, since I am not able to speak Arabic and Lao. Therefore I had to work together with interpreters; on the one hand they translated my questionnaires and on the other hand they helped me on site in my field research.

I also acted as a participant observer in the selected Internet cafés. This enabled different 
observations concerning the cafés' equipment and the nature of the clients. The combinations of all these research techniques facilitated the researcher to gain a comprehensive understanding of the ICT situation in the opted countries, especially regarding the Internet.

Finally, I want to mention that at international conferences and within reviews of journal articles I have submitted, it has been brought to my attention that the research I am engaged in can come across as an imperialistic attempt to influence the cultures I research. I want to debilitate this argument by arguing that I am not making any profit, in contrary, the whole research is self-funded. Moreover, only researchers from the wealthy Western world can afford to take out such a costly comparative study and thereby raise the awareness of this global problem.

\section{Conclusion}

The aim of this paper is to introduce the methodology for my dissertation thesis, which consists of my theoretical understanding and my empirical framework. The primarily goal of my thesis is to find out how ICTs can be implemented and used to foster sustainable development, especially in Least Developed Countries. By explaining the current situation of ICTs for development, which has to be considered as a Western hegemonic project, I wanted to clarify that at the moment exactly the opposite happens and that a new form of colonialism driven by economy and ICTs has been emerging. This so termed eColonialism was discussed taking into consideration the dimensions of society (ecological, political, cultural and technological) to bring to light how the (post)-industrialized high-income economies in the West benefit at the expense of the developing world. To counteract this imperialistic development, I proposed a working definition of sustainability, from which I deduced strategies of how to use ICTs to enhance sustainable development. During the process of elaborating my thesis, these strategies will be further elaborated with the help of my empirical results.

\section{References}

Alleyne, B. W. (1999). Cultural Politics and Globalized Infomedia. Interventions - International Journal of Postcolonial Studies, 1(3), 361-372.

Bichler, R. M. (2007). Information and Communication Technologies for Least Developed Countries (ICTs4LCDs): Exemplified in the Republic of Yemen. The International Journal of Interdisciplinary Social Sciences, 2(2), 349-360.

Bichler, R. M. (2008a). Information and Communication Technologies in the Republic of Malawi: An Assessment of Progress and Challenges Ahead. In A. O. Bada \& P. Musa (Eds.), Proceedings of the IFIP WG 9.4 Joint Workshop at University of Pretoria: Towards an ICT Research Agenda for African Development (pp. 189-202). Pretoria: International Federation for Information Processing.

Bichler, Robert M. (2008b): Southern Africa and the Digital Divide: A Malawian Case Study. In: The International Journal of Technology, Knowledge and Society. Vol. 4, No. 6. pp. 41-50. Boyd-Barrett, O. (2006). Cyberspace, globalization and empire. Global Media and Communication, 2(1), 21-41.

Braga, C. A. \& Kenny, C. \& Qiang, C. \& Crisafulli, D. \& Martino, D. D. \& Eskinazi, R. \& Schware, R. \& Kerr-Smith, W. (2000). The networking revolution: Opportunities and challenges for developing countries (working paper). Washington DC: World Bank Group. Retrieved April 15th, 2007, from http://www.infodev.org/library/working.html

Castells, M. \& Linchuan Qiu, J. \& Fernandez-Ardevol, M. \& Araba, S. (2006). Mobile Communication and Society. A Global Perspective. Cambridge, MA: MIT Press.

Correa, C. M. (2004). The WIPO Patent Agenda: The Risks for Development Countries. Working Chapter, no. 12, South Centre. Retrieved April 15th, 2007, from http://www.southcentre.org

European Information Technology Observatory (EITO) (2002). Jahrbuch 2002. Frankfurt/Main: EITO.

Fuchs, C. (2006). Towards a Global Sustainable Information Society (GSIS)? tripleC, 4(1), 40-99.

Fuchs, C. \& Blachfellner, S. \& Bichler, R. M. (2007). The Urgent Need for Change: Rethinking Knowledge and Management. In C. Stary \& F. Barachini \& S. Hawamdeh (Eds.), Knowledge Management: Innovation, Technology and Cultures. Series on Innovation and Knowledge Management - Vol. 6. Proceedings of the 2007 International Conference on Knowledge Management (pp. 293-307). New Jersey, London, Singapore: World Scientific.

Habermas, J. (1987). The Theory of Communicative Action: the Critique of Functionalist Reason (Vol. 2). Cambridge: Polity Press. 
Hofkirchner, W. \& Fuchs, C. \& Raffl, C. \& Schafranek, M. \& Sandoval, M. \& Bichler, R. (2007). ICTs and Society: The Salzburg Approach. Towards a Theory for, about, and by means of the Information Society (Research Paper No. 3 , ISSN 1990-8563). Salzburg: University of Salzburg, ICT\&S Center. Retrieved December 3, 2008, from http://icts.sbg.ac.at/media/pdf/pdf1490.pdf

The Malawi Communications Regulatory Authority (MACRA) (2007). Telecommunications Sector Status in Malawi and expected Benefits from the Connect Africa Summit. Draft Paper.

Mansell, R. \& Wehn, U. (Eds.) (1998). Knowledge Societies. Information Technology for Sustainable Development. Oxford: Oxford University Press.

McPhail, T. (1981). Electronic Colonialism: The Future of International Broadcasting and Communication. London: Sage Publishers Inc.

McPhail, T. (2008). eColonialism Theory: Hegemony and the Role of American Media. The Global Studies Journal, 1(2), 4553.

Mwesige, P. G. (2004). Cyber elites: a survey of Internet Café users in Uganda. Telematics and Informatics, 21, 83-101.

Ngwenyama, O. \& Andoh-Baidoo, F. K. \& Bollou, F. \& Morawczynski, O. (2006). Is there a Relationship between ICT, Health, Education and Development? An Empirical Analysis of five West African Countries from 1997-2003. The Electronic Journal on Information Systems in Developing Countries (EJISDC), 23(5), 1-11.

Okpaku, J. (Ed.) (2003). Information and Communication Technologies for African Development. An Assessment of Progress and Challenges Ahead. New York: United Nations ICT Task Force.

Schwarzer, S. \& De Bono, A. \& Giuliani, S. \& Kluser, S. \& Peduzzi, P. (2005). E-waste, the hidden side of IT equipment's manufacturing and use. Retrieved May 10th, 2008, from Environmental Alert Bulletin Web site: http://www.grid.unep.ch/product/publication/download/ew ewaste.en.pdf

Serageldin, I. (1995). The Human Face of the Urban Environment. In I. Serageldin, et al. (Eds.), Proceedings of the Second Annual World Bank Conference on Environmentally Sustainable Development: The Human Face of the Urban Environment. Washington, D.C., September 19-21, 1994 (pp. 16-20). Washington, D.C.: World Bank.

Sloterdijk, P. (2006). Im Weltinnenraum des Kapitals. Frankfurt am Main: Suhrkamp.

United Nations educational, Scientific and Cultural Organization (UNESCO) (2004). UNESCO and Microsoft Sign Cooperation Agreement to Help Bridge the Digital Divide. Retrieved May 10th, 2008, from http://portal.unesco.org/ci/en/ev.php-URL_ID=17504\&URL_DO=DO_TOPIC\&URL_SECTION=201.htm|

United Nations (2002-2005) The Criteria for the identification of the LDCs. Retrieved April 15th, 2008, from http://www.un.org/special-rep/ohrlls/ldc/ldc\%20criteria.htm

Wilson, E. J. III (2004). The Information Revolution in Developing Countries. Cambridge, MA: MIT Press.

Widmer, R. \& Oswald-Krapf, H. \& Sinha-Khetriwal, D. \& Schnellmann, M. \& Böni, H. (2005). Global perspectives on ewaste. Environmental Impact Assessment Review, 25, 436-458.

Williams, E. D. \& Ayres, R. U. \& Heller, M. (2002). The 1.7 Kilogram Microchip: Energy and Material Use in the Production of Semiconductor Devices. Environmental Science \& Technology, 36(24), 5504-5510.

World Commission on Environment and Development (WCED) (1987). Our Common Future. Oxford: Oxford University Press.

World Summit on Sustainable Development (2002). The Jo'burg Memo. Fairness in a Fragile World. Berlin: Heinrich Böll Foundation.

Ya'u, Y. Z. (2005). Globalisation, ICTs, and the New Imperialism: Perspectives on Africa in the Global Electronic Village. Africa Development, 30(1\&2), 98-124.

\section{About the Author}

Robert M. Bichler

(1979) received his master in Communication Science. From 2002-2004 he worked as a Teaching Assistant at the Institute for Communication Science at the University of Salzburg. In December 2004 he joined the Internet \& Society unit of the ICT\&S Center at the University of Salzburg as a Research and Teaching Assistant.

Robert's research is focused on the sustainable use of Information and Communication Technologies, especially in Least Developed Countries. 